\title{
ВИРТУАЛЬНОСТЬ КАК АТРИБУТ ПРОСТРАНСТВА И ВРЕМЕНИ СОВРЕМЕННОГО СОЦИУМА
}

\section{В.Н. Сокольчик}

Социальное пространство и социальное время относятся к важнейшим онтологическим основаниям бытия социума, оформляющим бытие современной цивилизации. Параметры социальных пространства и времени во многом определяют образ реальности в сознании современного человека. Тем не менее, социальное пространство и время не совпадают по своим характеристикам с объективно-научным восприятием и объяснением этих феноменов. Социальное пространство и время, во-первых, личностно ориентированы и субъективно наполнены, а, во-вторых, подвержены постоянным динамическим изменениям, сопутствующим и порой предвосхищающим развитие социума. Так, характеризуя социальное пространство, П. Бурдье в статье «Физическое и социальное пространство» писал о том, что оно является «объективацией и натурализацией прошлых и настоящих социальных отношений» $[1$, с. 53$]$.

Важнейшей характеристикой социального пространства и социального времени XXI века, тесно связанной с процессами информатизации и медиатизации общества, является виртуальность. Вне феномена виртуальности вообще невозможно понять сущность современной цивилизации, выявить ее характерные особенности, атрибутивные характеристики и воспринять уклад ее жизни.

В контексте развития информационных технологий трансформация термина «виртуальность» изменяется от характеристики состояния реальности (ирреальности) объекта (окружающего нас мира) к 
современному пониманию виртуальности как состояния сознания воспринимающего субъекта, в котором грань между реальным и сконструированным мирами фактически стирается. Отчасти в современном дискурсе происходит метафизическое сближение понятий симулякр и виртуальность, с той разницей, что симулякр претендует на то, что он обозначает объект, а виртуальность - состояние и процесс.

Изучение феномена существования человека в информационном обществе и виртуализацию жизни как следствие информатизации одними из первых начали рассматривать представители постмодернизма (Ж. Бодрийяр, Ж. Делез, Ф. Гваттари, У.Эко и др.). Ими осмыслены парадоксы работы с информационными технологиями (например, феномен «компьютерного отчуждения»), понятие «виртуальной реальности», симулирующей действительность и превращающей человека в объект манипулирования. Проблемы информационного общества и влияние виртуальности на жизнь социума поднимали и такие известные авторы как Е. Масуда, М. Кастельс, М. Маклюэн, А.В. Гулыга и мн. др. В тоже время виртуальность в аспекте ее влияния и проявления в социальном времени и пространстве остается малоизученной, несмотря на то, что виртуальная реальность прочно вошла в жизнь социума и «проникла» во все его сферы и институты.

Феномен устойчивости и даже незыблемости пространства, в котором существует социум, виртуальностью разрушается. Виртуальность привносит в субъективное ощущение пространства текучесть и непостоянство, объективируя симуляции и симулякры. При этом реальность становится фантомом, обманом, а ирреальность и симуляция объективной данностью. Применительно к описанию современного социума можно даже говорить о формировании особой «вирто-сферы», которая существует в среде «вирто-пространства» и «вирто-времени». Как считает автор теории «виртуального общества» немецкий социолог А.Бюль, с развитием технологий виртуальной реальности компьютеры из вычислительных машин превращаются в универсальные машины по производству «зеркальных» миров, пространство которых существует фактически объективно, но формируется по законам новой реальности [8].

Виртуальность как новый атрибут социального пространства, порожденный информатизацией общества, активизирует процесс объективации идей, стимулируя моделирование и существование их в пространстве социума вне материального посредника. Благодаря виртуальному пространству человек развивает новые виды деятельности: например, он уже не только создает образы, но легко манипулиру- 
ет ими, «вживляет» их в ткань повседневности, придает им культурный контекст, транслирует любому адресату и т.д. Правда, в результате возникают не артефакты культуры, а виртуальные «симулякры» (двойники, точные копии действительности, вместе с тем реально не существующие), подчиняющиеся собственной логике и живущие собственной жизнью.

Олицетворением виртуальности пространства социума XXI века становится информационная сеть Интернет, гигантская паутина, не только опутывающая пространство, но и реально созидающая новую реальность и формирующая совершенно новую социальную организацию. Сегментом порожденных виртуальностью организаций становятся виртуальные сообщества - новообразования, которые являются по сути и статусу симуляциями или даже симулякрами воображаемой реальности. Примерами могут служить виртуальный бизнес и финансовое партнерство, виртуальные молитвенные собрания, виртуальные игровые группы и корпорации, виртуальные совместные проекты и даже (!) виртуальный секс и виртуальные кладбища.

Отличной от традиционной и общепринятой в виртуальном пространстве становится система коммуникации индивидов и самовосприятия личности. Коммуникация в виртуальном пространстве вытесняется иллюзией, при этом реальность общения заменяется симуляцией последнего. Каждый может «поболтать в чате», через социальные сети связаться с друзьями, знакомыми и незнакомыми, однако в большинстве случаев в такой коммуникации присутствует не реальная личность, а ее виртуальный образ (аватар), идеализированный сообразно ситуации и не существующий вне виртуального пространства компьютерной реальности.

Безусловно, поколение, привычно ощущающее себя свободно в виртуальной среде, никогда не откажется от всемогущества, предлагаемого виртуальным общением. Без мобильности, быстроты и вседозволенности, создаваемыми виртуальной средой, современный человек себя уже не представляет. Однако платой за эти реалии является суррогатный характер такого вида коммуникации: виртуальное пространство не абсолютно тождественно реальному, а виртуальное общение не является адекватной заменой живого непосредственного контакта между людьми, скорее - прообразом зарождающейся коммуникации аватаров. Человек информационного общества, проводящий большую часть жизни в пространстве Интернета, постепенно растворяется в виртуальном пространстве и теряет целостность собственной личности среди симуляций, утрачивая адекватность самовосприятия. 
Коммуницируя с фантомами, сам являясь своего рода фантомом (аватар-маска, реальность которой предполагается, но не гарантируется), человек, живущий в виртуальном пространстве компьютерной сети, начинает путать реальность и сеть, истинное и фантазийное, правду и вымысел. Человек эпохи модерна - эпохи доинформационной, осмысляющий себя в социальной жизни, воспринимает реальность как объективную данность, как естественную необходимость, в которой приходится жить и коррелировать свои действия сообразно внешней довлеющей реальности. Человек эпохи постмодерна и информационного общества, погруженный в виртуальную реальность, увлеченно «живет» в ней, при этом сознавая ее условность, управляемость параметров, предполагает возможность выхода или, наоборот, «зависания» в виртуальном пространстве. Вследствие этого «погружения» перспектива того, что отношения между людьми примут форму отношений между образами, становится наиболее реальной перспективой виртуализации общества. Так, в современном обществе симуляций происходит переход от стабильного и самобытного (идентичного) «я», где самость воспринимается как нечто постоянное, на изменчивое «я», понимаемое как процесс, не имеющий константных точек и позиций. В этом контексте появляется возможность трактовать общественные изменения в пространстве современной цивилизации с помощью дихотомии реальное/виртуальное, где взаимодействия между людьми могут осуществляться и реально, и ирреально - как виртуальные аналоги реальных социальных взаимодействий. Смешение реального и виртуального, возможного и невозможного приводит к тому, что исполнение социальных ролей все чаще заменяется симуляцией, атрибуты институциональности замещаются фантомами, коммуникативное пространство стабильности переходит в пространство потоков, сетей и симуляций.

По нашему мнению, знаменитое выражение М. Маклюэна, в котором пространство информационного общества трактуется как «глобальная деревня» [6, с. 47], уже не отвечает реалиям виртуального пространства социума XXI века. Краткосрочность общения, неустойчивость и кратковременность социальных связей, симуляционный характер отношений, отсутствие устойчивых духовных установок, противоречивость коммуникативных принципов - эти характеристики более адекватно описываются термином «глобальный мегаполис». Последний является образом и одновременно слепком современной социальной действительности, укорененной в виртуальной среде и выражающей конфликт людей, вынужденно связанных между собой условиями 
образа жизни мегаполиса, но имеющих право на независимую личную жизнь.

Таким образом, жизнь современного человека протекает сегодня не столько в пространстве объективного мира, сформированного разумом, традициями культуры, биологическими закономерностями, сколько в пространстве фантомном, подчиненном законам виртуальности и симуляциям.

Тесно связано с концептуальным определением пространства современной цивилизации как виртуального и определение социального времени. Последнее неотделимо от пространства, по сути, являясь его проекцией. Рассматривая идею социального времени (социотемпоральности) в своих работах известный исследователь проблемы времени Дж. Фрейзер пишет о том, что социальное время воспринимает историческое и психологическое время сквозь призму существования и предпочтений современного общества [9, с. 14]. Таким образом, социотемпоральность отличается неуниверсальностью времени, его зависимостью от людей, восприятий, социотехнологий и др. Интересна идея Фрейзера о том, что социотемпоральность включает в себя разделение на «время ощущаемое и время понимаемое». «Время понимаемое» относительно объективно и встраивается в пирамиду темпоральностей Фрейзера (см., напр.: [3]), но «время ощущаемое» (по Фрейзеру, оно является порождением научно-промышленной цивилизации и своего рода коллективной шизофренией) абсолютно субъективно не только на личностном, но и на общественном уровне.

Специфической характеристикой социального времени современной эпохи является его виртуальность. «Вирто-время» можно сжимать и развертывать, направлять вспять (инверсия времени) или же в будущее, работать с ним, нарушая все известные законы объективного мира (в целом на этом строятся и компьютерные эксперименты, и компьютерные игры). Виртуальное время, являющееся прерогативой «вирто-сферы», в силу тотальной компьютеризации общества постепенно переносится в реальную жизнь социума.

К.Ю. Галкин в своем размышлении о виртуальном времени пишет о преимуществах его в аспекте восприятия социума:

Реальное время - все старит, снимает покров иллюзорности, виртуальное время - напротив, создает иллюзию всесильности над вечностью и энтропией, обольщая человека надеждой на бессмертие [2].

Виртуальное время характеризуется «неуниверсальностью» (специфичностью), т. е. своего рода индивидуальностью; дискретно- 
стъю - адекватным сочетанием линейного и циклического понимания хода времени; обратимостъю как возможностью исправить ошибки и переиграть сложившееся; беспределъностъю как победой над конечностью и, значит, ограниченностью человека и цивилизации в целом; неравномерностъю хода, что позволяет социуму вписываться в неразмеренный, убыстряющийся ритм постиндустриального общества [7, c. 193]. Особенную позитивную окраску виртуально трактуемому времени придает кажущаяся несерьезность, легкость и «вседоступность» (вседозволенность) нового социального времени XXI века.

Собственно виртуальность как черта социального времени постиндустриальной цивилизации, породила и новые отношения между людьми - отношения отчасти виртуальные, а именно временные и ускоренно-облегченные (которые точно отражает сленговое выражение «не заморачиваться»), неукорененные.

Еще одна черта социального «вирто-времени» современной информационной цивилизации - иллюзия свободного распоряжения и управления временем. Виртуальное время подвластно социуму и его «прихотям», следовательно, оно не является независимым и объективным, постоянным, стабильным и размеренным. Социальная темпоральность, сформированная обществом XXI века, предполагает такой функциональный подход к времени, который подчеркивает иллюзорность и субъективность последнего: возможность ускорить время (улучшить динамику процессов), «перевернуть время» (перевод часов), обогнать или затормозить время (перелететь на самолете через несколько часовых поясов), структурировать время и соответственно его подчинить (сезонная работа, учеба, долгосрочные планы и пр.). Впрочем, это глобальное управление виртуальным временем вопреки внешней иллюзии не создает естественного ритма, подвластного человеку, а вводит в действие некий функционал, постепенно подавляющий и разрушающий индивида [5, с. 432]. В этом контексте личность становится зависимой от сконструированных социумом виртуальных обстоятельств (виртуальных циклов, ритмики процессов).

Интересно, что те характеристики, которые привносит в восприятие времени виртуальность, одинаково необходимы для современной науки с ее дилеммами и парадоксами (виртуальность времени позволяет сочетать несочетаемое, реализовать принцип дополнительности и исключить строгий детерминизм, предлагая свободу трактовки событий (фактов), свободу эксперимента, свободу прогнозов) также необходимы и для индивида, поскольку позволяют иллюзиям всемогущества возобладать над реальностью бессилия. В поисках себя в усло- 
виях все большего погружения в реальность «вирто-сферы», человек все меньше ориентируется на «другого», соответственно все меньше видит себя «в зеркале другого» и все дальше уходит от объективного мира. Порождением виртуального времени становится личность, неадекватно оценивающая окружающее, личность, не стремящаяся к объективности мира-идеала, а живущая в иллюзии реальности фантомов. Мир и социум для индивида превращаются в разупорядоченную реальность - события наслаиваются, не уходя в прошлое, сосуществуют с нынешними и даже будущими.

Процесс этот, безусловно, закономерен и, хотя воздействие виртуальности на социальное время тревожит психологов, социологов и просто думающих людей, вряд ли это можно остановить или предотвратить дальнейшее тотальное распространение. Для адаптации личности и социума в целом к современным условиям бытия, в т. ч. к социальному времени и пространству, обществу настоятельно требуются разработки новых социальных механизмов стабилизации культурно-коммуникативных процессов, упорядочения коммуникативного пространства, усиление доверия к науке нового века - ее объясняющей и прогнозирующей функции. Только научившись противостоять деструктивному влиянию быстротечности, фрагментарности, иллюзорности и нестабильности социального пространства и времени современной цивилизации человечество сможет адекватно воспринять будущее и совершенствовать свой жизненный мир.

М. Кастельс писал:

История только начинается, если понимать под ней то, что после тысячелетий доисторической битвы с природой, сначала выживая в борьбе с ней, а затем покоряя ее, человеческий вид вышел на такой уровень знаний и социальной организации, который дает нам возможность жить в преимущественно общественном мире. Речь идет о начале иного бытия, о приходе нового, информационного века, отмеченного самостоятельностью культуры по отношению к материальной основе нашего существования. Но вряд ли это может послужить поводом для большой радости, ибо, оказавшись в нашем мире наедине с самими собой, мы должны будем посмотреть на свое отражение в зеркале исторической реальности. То, что мы увидим, вряд ли нам понравится [4, c. 505].

Социальное пространство и социальное время - реальные атрибуты существования социума. Их характеристики, свойства, особенности формируют картину мира и образ общества в понимании человека. Отнюдь не объективные научные представления о пространстве и времени, а социально сформированные конструкты последних оказывают 
влияние на нашу повседневную жизнь, формируя ее стиль, строй и ритм. Все больше подпадая под порабощение социального обустройства жизни, человек оказывается все дальше от объективности и размеренности мира природы и все сложнее различает истину и ложь, реальность и симуляцию, виртуальные и действительные возможности.

\section{Литература}

[1] Бурдъе П. Физическое и социальное пространства // Социология социального пространства. - СПб. : Алтейя, 2007.

[2] Галкин К.Ю. Размышление о виртуальном времени [Электронный ресурс].-Режим доступа: http://bibliofond.ru/view.aspx?id $=105427 \sharp 1$.

[3] Гансвинд И.Н. Дж.Т.Фрейзер и его теория времени [Электронный ресурс].-Режим доступа: http:// www.chronos.msu.ru/old/RREPORTS/gansvind_o_freizere.htm

[4] Kaстельс M. Становление общества сетевых структур // Новая постиндустриальная волна на Западе. - М. : Academia, 1999. C. 494-505.

[5] Kастельс M. Информационная эпоха: экономика, общество и культура. - М. : ГУ ВШЭ, 2000.

[6] Мак-Люэн М. Галактика Гуттенберга. Сотворение человека печатной культуры. - К. : Ника-Центр, 2003.

[7] Сокольчик В.Н. Время, порожденное социумом 21 века, и его влияние на человека и общество // Системная трансформация общества: инновации и традиции. - Брест, 2013. - Вып. 10. - С. 191194.

[8] Bühl A. Die virtuelle Gesellschaft des 21. Jahrhunderts: sozialer Wandel im digitalen Zeitalter. - Wiesbaden: Westdeutscher Verlag, 2000 .

[9] Fraser J.T. A Backward and Forward Glance // Study of Time IV. N.Y., 1981.

Надійшла до редакцї̈ 10 червня 2016 р. 


\section{Анотація}

Сокольчик В.М. Віртуальність як атрибут простору і часу сучасного соціуму

Стаття присвячена характеристиці соціального часу і соціального простору сучасної інформаційної цивілізації. Автор розглядає нові цінності, характеристики суспільства, комунікативні практики і відносини, що виникли внаслідок існування суспільства у віртуальному просторі і віртуальному часі.

Ключові слова: соціальний простір, соціальний час, віртуальність, симулякр, інформаційне суспільство.

\section{Abstract}

Sokolchyk V.M. Virtuality as an attribute of space and time of the modern society

The paper is devoted to a characterization of a social time and social space of the moder informational civilization. The author considers new values, characterizations of society, communicative practices and relationships arising due to social existence in a virtual space and virtual time.

Keywords: Social space; social time; virtuality; simulacrum; information society

\section{References}

1. Burdje P. Fizicheskoe i socialnoe prostranstva // Sociologiya socialnogo prostranstva. — SPb. : Altejya, 2007.

2. Galkin K.YU. Razmyshlenie o virtualnom vremeni : http://bibliofond.ru/view.aspx?id=105427]1.

3. Gansvind I.N. Dzh.T. Frejzer i ego teoriya vremeni : http:// www.chronos.msu.ru/old/RREPORTS/gansvind_o_freizere.htm

4. Kastels M. Stanovlenie obshchestva setevyh struktur // Novaya postindustrialnaya volna na Zapade. — M. : Academia, 1999. - C. 494-505.

5. Kastels M. Informacionnaya ehpoha: ehkonomika, obshchestvo i kultura. M. : GU VSHEH, 2000. 
6. Mac-Luen M. Galaktika Guttenberga. Sotvorenie cheloveka pechatnoj kultury. — K. : Nika-Centr, 2003.

7. Sokolchik V.N. Vremya, porozhdennoe sociumom 21 veka, i ego vliyanie na cheloveka i obshchestvo // Sistemnaya transformaciya obshchestva: innovacii i tradicii. — Brest, 2013. - Vyp. 10. — C. 191- 194.

8. Bühl A. Die virtuelle Gesellschaft des 21. Jahrhunderts: sozialer Wandel im digitalen Zeitalter. — Wiesbaden : Westdeutscher Verlag, 2000.

9. Fraser J.T. A Backward and Forward Glance // Study of Time IV. - N.Y., 1981. 